\title{
Effect of moisture buffering on surface temperature variation: study of different indoor cladding materials
}

\author{
Clémence Legros ${ }^{1,2, *}$, Amandine Piot ${ }^{1}$, Monika Woloszyn ${ }^{2}$, and Mickael Pailha ${ }^{2}$ \\ ${ }^{1}$ University of Grenoble Alps, CEA, LITEN, INES, Grenoble, France \\ ${ }^{2}$ University of Savoie Mont Blanc, CNRS, LOCIE, Chambéry, France
}

\begin{abstract}
The building materials used indoors constantly interact with the environment in which the occupants live. Recent studies have shown that natural materials, such as wood, can improve human wellbeing. In addition, the building materials facing the indoor air are able to adsorb and desorb water vapour from their surface and exchange it with the surrounding air. This mass exchange comes along with heat exchange, modifying their surface temperature, and thus the indoor environment. Therefore, in this article, we are investigating whether moisture buffering has an impact on comfort. For this purpose, room-scale numerical simulations have been carried out with WUFI Plus, comparing two types of interior cladding materials: painted plasterboards and a raw spruce panelling. The results show a slightly lower surface temperature and air temperature during the summer period when using spruce. A higher hygroscopicity of the spruce than the gypsum can explain this difference in behaviour between the two studied materials. Thus, spruce exchanges more latent heat with the surrounding air. However, only this thermal difference cannot explain the difference in comfort perception between the gypsum and the wood.
\end{abstract}

\section{Introduction}

In the current environmental context, the energy performance of buildings is increasingly an issue. However, it does not make sense to deal with energy performance if indoor comfort is not guaranteed.

At the same time, the building industry is increasingly using materials with a low carbon footprint, such as biosourced materials (wood, cork, straw, hemp, cellulose wadding, etc).

Several studies have shown that materials used indoors can affect human well-being [1], [2]. For example, in France, many people claim that the perceived comfort is better inside a wooden room, compared to a room made of plasterboards. Then, we can wonder: do the materials in contact with the indoor air of buildings significantly affect the comfort felt by the occupant?

Comfort is a subject that has been much studied in recent decades. However, it still lacks a general definition that has been agreed upon by the scientific community. It can be explained, inter alia, by its subjectivity and its interdisciplinary nature (psychology, physiology and building physics).

From a psychological point of view, several studies have been carried out on the subject. For example, Rice conducted an experiment on 119 people. The reaction of participants to the presence of wood in a room is extremely positive [3]. Boulet found a similar trend: wood-based rooms are often better evaluated subjectively than objectively [4].
From a building physics point of view, for moderate thermal environments and steady-state conditions, the human body is a heat engine and comfort is achieved when thermal equilibrium is maintained with the surroundings. Four main environmental factors are impacting the thermal comfort (air temperature, mean radiant temperature, air speed and relative humidity) and two personal factors (metabolic rate and clothing insulation) [5]. Obviously, the building materials used indoors do not affect the metabolic rate, the clothing insulation or the air speed. This means that, if there is a physical explanation for the difference in perception, then the air temperature, the radiant temperature and the relative humidity should be investigated. Numerous studies have already shown that rooms made of hygroscopic materials have a particular behaviour. With such indoor cladding materials, water vapour exchanges take place between their surface and the surrounding air. Therefore, the materials facing the indoor air can more or less damp the changes in air relative humidity [6]. From a thermal point of view, since these mass exchanges come along with heat exchanges, we want to determine how much they modify the surface temperature of the materials. A previous work stated that, usually, the vapour exchanges have only a low impact on the operative temperature and are highly dependent on the properties of the materials, the occupancy schedule and the ventilation rate [7]. The present article follows this previous work and pays special attention to the surface temperature and latent heat exchanges due to water vapour exchanges between materials and their environment.

\footnotetext{
Corresponding author: legros.clemence@outlook.fr
} 
The article is organized as follows: first, a literature review presents the context of our study. Then the method adopted is described. Finally, the results are presented and discussed.

\section{State of the art}

The human body continuously generates heat. It is exchanged with the environment either in sensible form, due to temperature variations, or in latent form, due to the phase change of water on the skin surface. Several physical phenomena occur [8]:

- conduction between skin or clothing and other solids (around 3\%),

- convection between skin or clothing and air and through the respiratory tract (around 15\%),

- solar radiation and long-wave radiation between walls and skin or clothing (around 60\%),

- evaporation through perspiration and breathing (around $22 \%)$.

To define the temperature perceived by the occupants, many indicators have been developed. However, no consensus has yet been reached on any of them and the operative temperature, defined in the standard ISO 7726 [9], is still widely used. It takes into account both convection and radiation. It is the uniform temperature of an imaginary black enclosure in which an occupant would exchange the same amount of heat as in the actual nonuniform environment. It is calculated according to Equation 1:

$$
T_{o p}=\frac{h_{r} T_{m r}+h_{c} T_{a i r}}{h_{r}+h_{c}}
$$

where $h_{r}$ and $h_{c}$ are the heat transfer coefficients of radiation and conduction respectively, $T_{m r}$ and $T_{\text {air }}$ are the mean radiant temperature and the air temperature respectively.

Each surface temperature has a direct impact on the mean radiant temperature $T_{\mathrm{mr}}$. Roughly, if we consider an occupant in the middle of a room, the mean radiant temperature can be estimated as the average of each surface temperature, weighted by their area. Thus, the temperature felt by the occupant is partly dependent on the surrounding surface temperatures. Wang conducted a full-scale experiment by questioning the occupants of a room as he changed the surface temperatures [10]. He concluded that both the air temperature and the temperature difference between the air and the surfaces affected the thermal sensation.

The construction building materials used indoors are usually hygroscopic. When they are uncoated, their surface layers can exchange water vapour with the surrounding air, under cyclic moisture loads. When the vapour pressure of the air is lower than the vapour pressure of the surface, the materials desorb. Humidity and latent heat of sorption are extracted from materials. As a result, the surface temperature decreases. When the vapour pressure of the air is higher than the vapour pressure of the surface, the opposite phenomenon occurs.
The walls adsorb moisture and latent heat of sorption is released from the materials. Thus, their surface temperature rises. Kraniotis conducted a room scale experiment with a wood-based prefabricated insulating sandwich panel. He showed that when the indoor relative humidity increases, the surface temperature of the interior solid wood component increases as well, up to $3^{\circ} \mathrm{C}$. He also noticed that it is also consistent with the increase of the indoor temperature. Thus, the heat released by the wooden structure has an impact on the indoor climate [11]. In addition, Nore showed that the surface temperature curve follows the same path as the curve for wood moisture content, showing the effect of latent heat of sorption [12].

In this study, we therefore propose to assess numerically the impact of a raw spruce panelling facing the indoor air, regarding the surface temperature and the air temperature.

\section{Method}

The experimental building presented on Figure 1 has been selected for this study. There are ongoing measurements in this house.

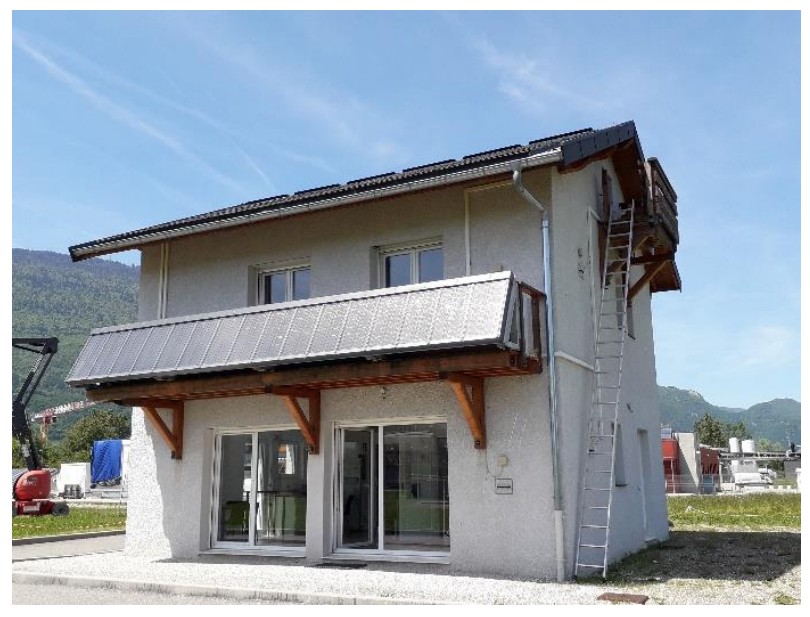

Fig. 1. The experimental house.

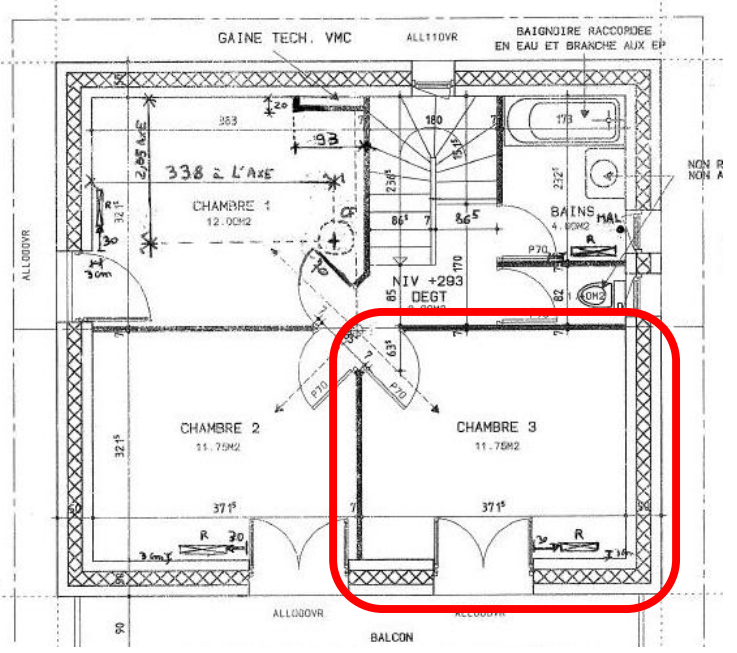

Fig. 2. Plan of the $1^{\text {st }}$ floor and presentation of the room studied. 
The house shown in Figure 1 was modelled with the widely used software WUFI Plus. It has been developed by Künzel and it has been validated by Antretter [13], [14] .For the purpose of this work, we studied the room located on the first floor. A plan is presented in Figure 2.

It is an $11.75 \mathrm{~m}^{2}$ and $31 \mathrm{~m}^{3}$ room. The south and east walls are facades facing the outside air. The north and west walls are indoor partition walls, in contact with similar indoor conditions. A $2.1 \mathrm{~m}^{2}$ French window opens onto a south-facing balcony.

As we only want to study the water vapour exchanges with vertical walls, the floor and the ceiling are vapourtight. They are sealed, respectively with tiles and a vapour barrier membrane. The composition of the vertical walls is presented in Table 1, from the outside to the inside.

Table 1. Vertical walls compositions.

\begin{tabular}{lc}
\hline \hline \multicolumn{1}{c}{ Wall facing the outside } \\
\hline Rendering & $1.5 \mathrm{~cm}$ \\
Brick & $15 \mathrm{~cm}$ \\
Mineral wool & $20 \mathrm{~cm}$ \\
Brick & $15 \mathrm{~cm}$ \\
Vapour barrier & $1.3 \mathrm{~cm}$ \\
Indoor cladding & $1.3 \mathrm{~cm}$ \\
\hline \multicolumn{2}{c}{ Partition wall facing the inside } \\
\hline Indoor cladding & $4 \mathrm{~cm}$ \\
Mineral wool & $1.3 \mathrm{~cm}$ \\
\hline Indoor cladding
\end{tabular}

The indoor cladding corresponds to either painted plasterboards or a raw spruce panelling. The materials are presented in Table 2 and the sorption curves of the plasterboard and the spruce are presented in Figure 3 and Figure 4, respectively.

Table 2. Material properties of the indoor claddings.

\begin{tabular}{lcc}
\hline \hline Properties & $\begin{array}{c}\text { Painted } \\
\text { plasterboards }\end{array}$ & $\begin{array}{c}\text { Raw spruce } \\
\text { panelling }\end{array}$ \\
\hline $\begin{array}{l}\text { Bulk density } \\
{\left[\mathrm{kg} / \mathrm{m}^{3}\right]}\end{array}$ & 1200 & 455 \\
$\begin{array}{l}\text { Porosity [-] } \\
\text { Specific heat capacity }\end{array}$ & 0.53 & 0.73 \\
$\begin{array}{l}{[\mathrm{J} / \mathrm{kgK}]} \\
\text { Thermal conductivity }\end{array}$ & 1000 & 1500 \\
$\begin{array}{l}\text { [W/mK] } \\
\text { Water vapour } \\
\text { diffusion factor [-] }\end{array}$ & 0.43 & 0.23 \\
$\begin{array}{l}\text { Sd-value of the } \\
\text { coating [m] }\end{array}$ & 7.5 & 4.3 \\
\hline \hline
\end{tabular}

The heat transfer resistances between the surface materials and the air have been defined according to the component type and the standard ISO 6946 [15]. The values used on the interior surfaces are presented in Table 3.
Table 3. Heat transfer resistances on the interior surface.

\begin{tabular}{lccc}
\hline \hline & Floor & Wall & Ceiling \\
\hline $\mathrm{R}_{\mathrm{si}}\left[\mathrm{m}^{2} . \mathrm{K} / \mathrm{W}\right]$ & 0.17 & 0.13 & 0.10 \\
\hline \hline
\end{tabular}

The room studied is a double bedroom. Thus, during the nighttime, there is a long and low-intensity step of heat and moisture gains. It is constant, according to the values presented in Table 4, over 9 hours. Only the human occupancy is taken into account, and there are no electrical appliances. During the daytime, there are no heat or moisture gains. This schedule occurs each day of the week, even during the weekend.

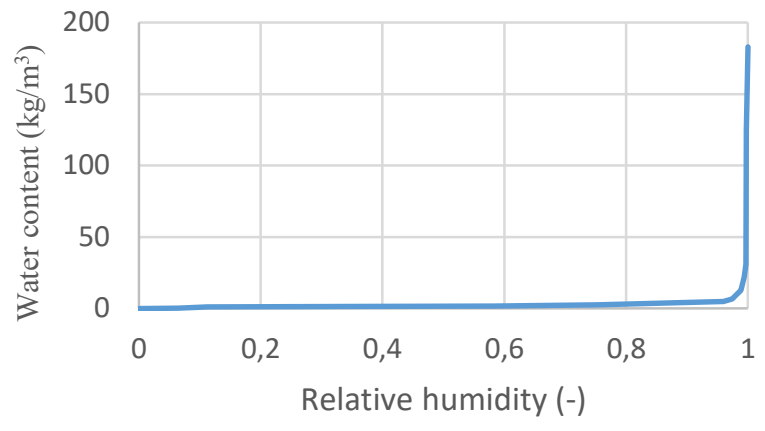

Fig. 3. Sorption curve of the plasterboard.

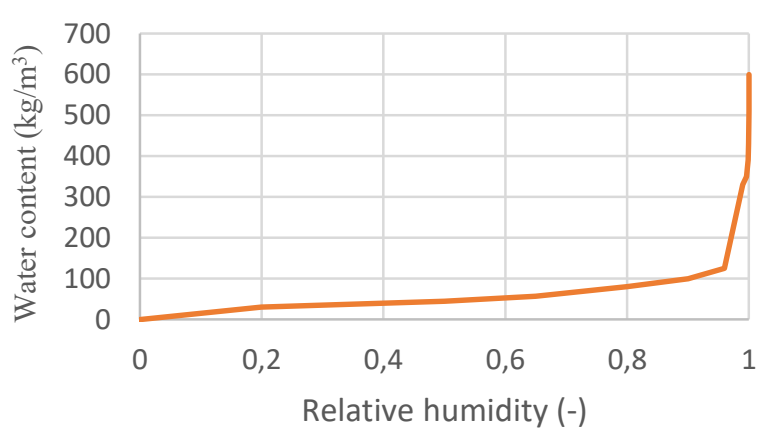

Fig. 4. Sorption curve of the spruce.

Table 4. Occupancy loads for a two people bedroom.

\begin{tabular}{ccc}
\hline \hline Bedroom & $\begin{array}{c}\text { Heat } \\
{[\mathrm{W} / \mathrm{h}]}\end{array}$ & $\begin{array}{c}\text { Moisture } \\
{[\mathrm{g} / \mathrm{h}]}\end{array}$ \\
\hline $22 \mathrm{~h}-7 \mathrm{~h}$ & 120 & 80 \\
$7 \mathrm{~h}-22 \mathrm{~h}$ & 0 & 0 \\
\hline \hline
\end{tabular}

The building is located in the French Alps. Thus, the weather file of Grenoble has been used for the simulations. This city is located at $215 \mathrm{~m}$ above the sea. It has a special climate due to the proximity of the mountains: large daily and seasonal temperature ranges, a lot of sunshine and significant rainfall.

The shutters remained closed throughout the simulations to avoid solar gains through the window.

The set-point temperature of the heating system is fixed at $19^{\circ} \mathrm{C}$. 
A blower door test on the experimental house determined that the infiltration was $0.115 \mathrm{vol} / \mathrm{h}$. This value was used in the simulations. The mechanical ventilation (supply) flow rate is constant and equal to $0.5 \mathrm{vol} / \mathrm{h}$.

To avoid the impact of the initial conditions defined for each material, three years were simulated (by repeating the same weather file), and only the results of the third year are presented and used for the following work.

\section{Results and discussion}

\subsection{Operative temperature}

As a first step, the overall behaviour of the room made up with painted plasterboards, named Gypsum thereafter, has to be compared to the overall behaviour of the room made up with raw spruce panelling, named Spruce thereafter. To do so, Figure 5 shows the evolution of the operative temperature for both rooms studied.

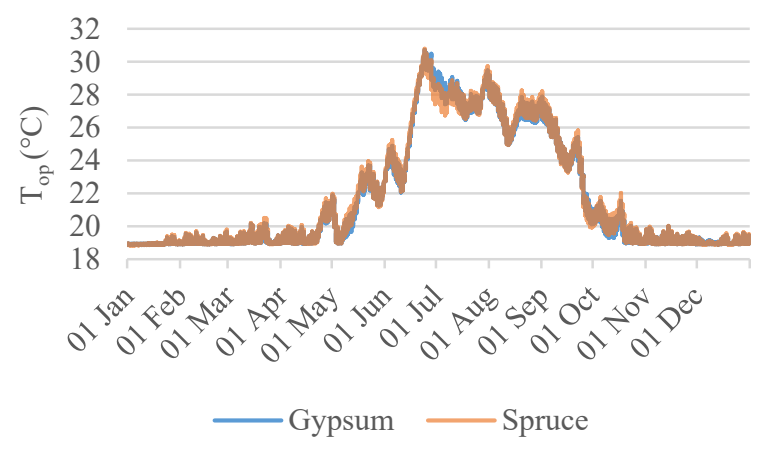

Fig. 5. Evolution of the operative temperature.

Both curves almost always overlap. It means that there is only a slight difference in behaviour between both rooms studied. For the sake of clarity, the difference between both curves is calculated according to Equation 2 .

$$
\Delta T_{o p}=T_{o p}(\text { gypsum })-T_{o p}(\text { spruce })
$$

The grey curve in Figure 6 shows the result of the calculation defined by Equation 2. The red areas stand for the heating period, from October $15^{\text {th }}$ to May $1^{\text {st }}$.

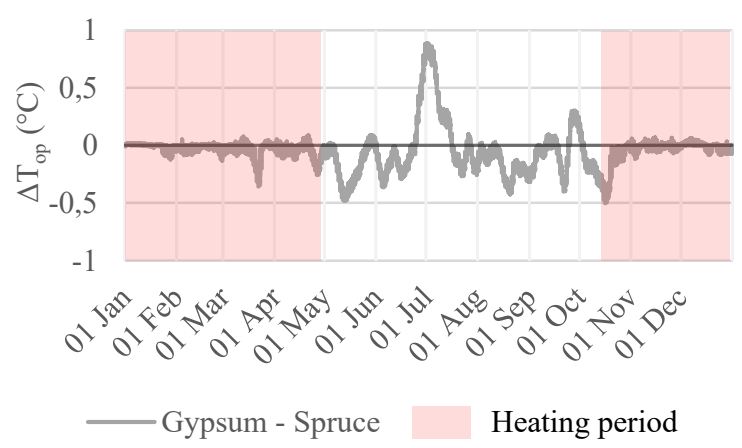

Fig. 6. Operative temperature differences between the room with plasterboards and the wooden room.
During the heating period, the differences in operative temperature $\Delta \mathrm{T}_{\mathrm{op}}$ between both rooms are very low. However, when the heating system switches down, these differences become more significant, ranging from $-0.5^{\circ} \mathrm{C}$ to $+1^{\circ} \mathrm{C}$. In July, when the maximum deviation is reached, the operative temperature in the room made up with plasterboards is about $1{ }^{\circ} \mathrm{C}$ higher than in the wooden room.

As a second step, since the air temperature and the surface temperature influence the operative temperature, each behaviour has to be studied.

\subsection{Air temperature}

As before, for the sake of clarity, Equation 3 calculates the air temperature difference between the room with plasterboards, named Gypsum thereafter, and the wooden room, named Spruce thereafter.

$$
\Delta T_{\text {air }}=T_{\text {air }}(\text { gypsum })-T_{\text {air }}(\text { spruce })
$$

The grey curve in Figure 7 presents the result of the calculation defined by Equation 3 .

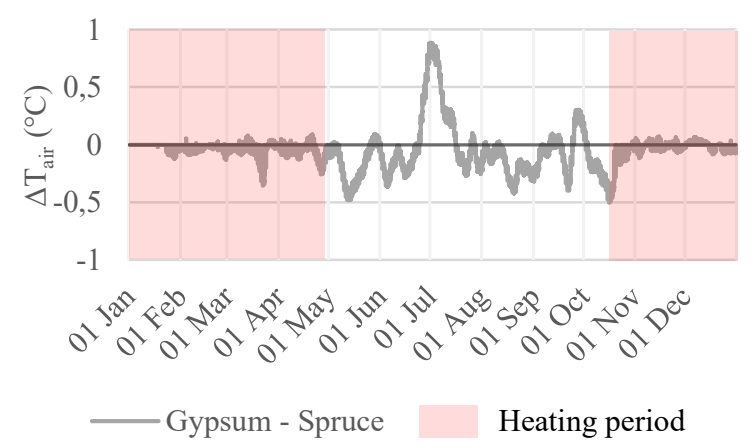

Fig. 7. Air temperature differences between the room with plasterboards and the wooden room.

Similarly, the differences in air temperature over the heating period are low. The heating system keeps the air temperature at the set point temperature in both rooms. When the heating system stops, the differences become more significant, ranging from $-0.5^{\circ} \mathrm{C}$ to $+0.9^{\circ} \mathrm{C}$, with a maximum at the beginning of July.

\subsection{Surface temperature}

As before, for the sake of clarity, the difference between the surface temperature of the painted plasterboards, named Gypsum thereafter, and the surface temperature of the raw spruce panelling, named Spruce thereafter, is calculated according to Equation 4.

$$
\Delta T_{\text {surf }}=T_{\text {surf }}(\text { gypsum })-T_{\text {surf }}(\text { spruce })
$$

The grey curve in Figure 8 presents the result of the calculation defined by Equation 4 . 


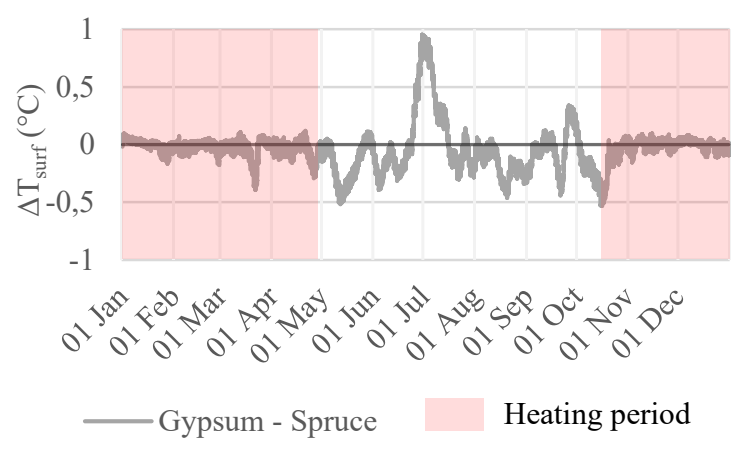

Fig. 8. Surface temperature differences between the room with plasterboards and the wooden room.

As before, during the heating period, the difference between the surface temperature of the gypsum and the spruce is little. As the air temperature is kept at a constant level, it is assumed that the surface temperature differences, which can be seen in Figure 8, are due to the latent heat of sorption. Conversely, when the heating system is switched off, the air temperature is no longer regulated and is directly linked to the surface temperature. To test these assumptions, simulations were carried out by activating the "Exclude latent heat of evaporation" option available in WUFI Plus.

Figure 9 shows the impact of latent heat of sorption on the surface temperature of materials. $\Delta \mathrm{T}_{\text {surf }}$ is calculated according to Equation 4. The red curve corresponds to a purely thermal simulation. Therefore, mass exchanges and latent heat of sorption are disregarded. The grey curve still corresponds to the hygrothermal simulation.

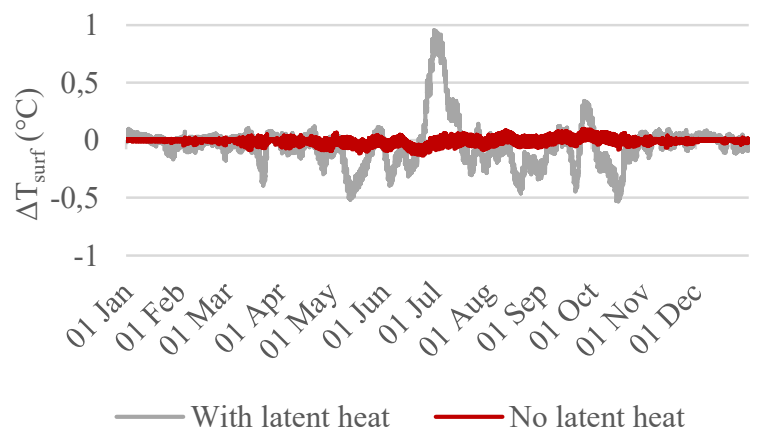

Fig. 9. Impact of the latent heat of sorption on the surface temperature.

When the latent heat of sorption is neglected, the gypsum and the spruce have a similar surface temperature. It means that the differences depicted by the grey curve in Figure 9 are due to the latent heat of sorption linked to the mass exchanges between the air and the surface of the materials.

To understand these discrepancies in surface temperature between the plasterboards and the spruce panelling, the impact of latent heat of sorption on the surface temperature has to be studied for each material. Thus, a difference between the surface temperatures without the latent heat and the ones with the latent heat is calculated according to the Equation 5.

$$
\begin{aligned}
\Delta \text { latent }_{\text {Tsurf }}= & T_{\text {surf }}(\text { no latent heat }) \\
& -T_{\text {surf }}(\text { with latent heat })
\end{aligned}
$$

Figure 10 and Figure 11 present the result of the calculation defined by Equation 5, for the plasterboards and the spruce panelling, respectively.

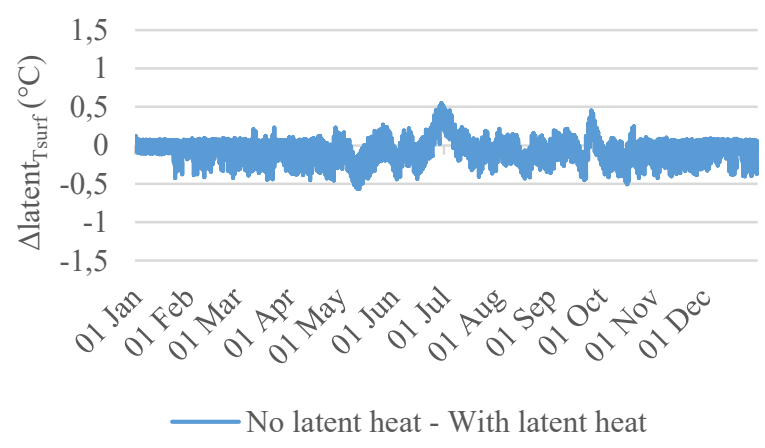

Fig. 10. Impact of the latent heat of sorption on the surface temperature of the plasterboards.

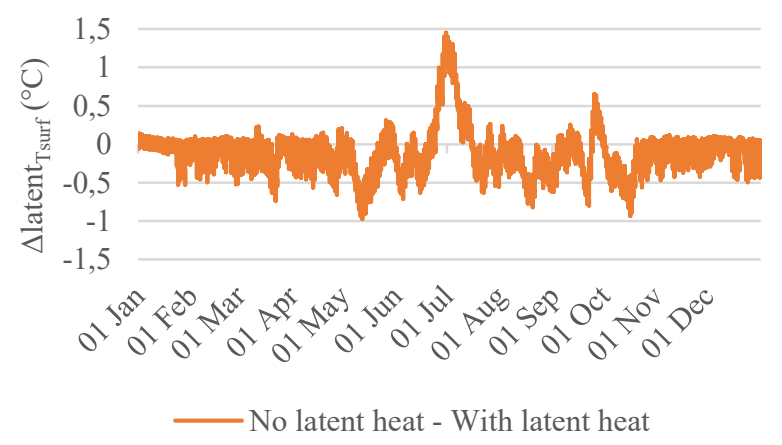

Fig. 11. Impact of the latent heat of sorption on the surface temperature of the spruce panelling.

As stated before, the higher differences occur during the summer, when the heating system is switched off, ranging from $-0.5^{\circ} \mathrm{C}$ to $0.5^{\circ} \mathrm{C}$ for the plasterboards and from $-1^{\circ} \mathrm{C}$ to $1.5^{\circ} \mathrm{C}$ for the spruce panelling. They are greater for spruce as it is a more hygroscopic material. Therefore, it stores and exchanges more water vapour with the surroundings.

The results presented so far show that indoor cladding affects the surface temperature and, therefore, the air temperature. However, most of the time, it is in the range of $\left[-0.5^{\circ} \mathrm{C} ; 0.5^{\circ} \mathrm{C}\right]$, and up to around $1^{\circ} \mathrm{C}$ at most. So we can wonder if the human body can feel such differences. It seems difficult to justify the difference in comfort perception by the occupants between a room with plasterboards and a wooden room solely on the basis of this difference in temperature. More likely, it is a combination of several factors that leads to this difference in perception. For example, many studies, including the one of Ojanen [6], have studied the moisture buffering effect on the relative humidity level in the air. The changes in humidity are dampened. However, its impact on the perceived comfort has not yet been quantitatively 
estimated. A rough estimation of the behaviour difference between both rooms can be made from Figure 12 and Figure 13. They present the operative temperature and the relative humidity of the air in the room made up, respectively with the plasterboards and the spruce panelling over a year. The yellow area corresponds to the comfort zone according to the standard NF EN 15251, for an existing building [16].

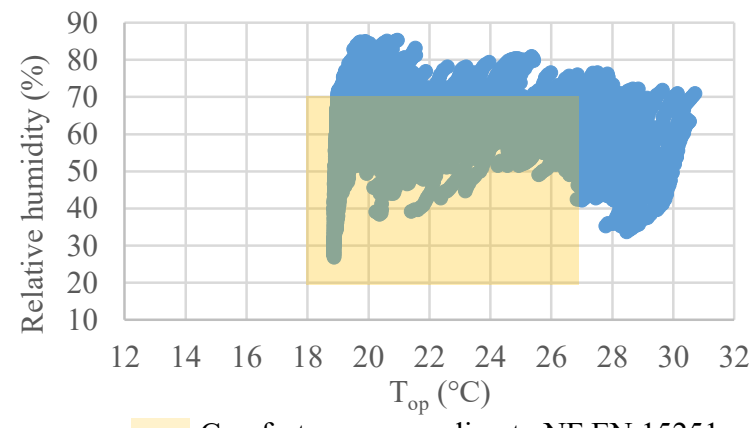

Comfort zone according to NF EN 15251

Fig. 12. Relative humidity and operative temperature in the room with the plasterboards.

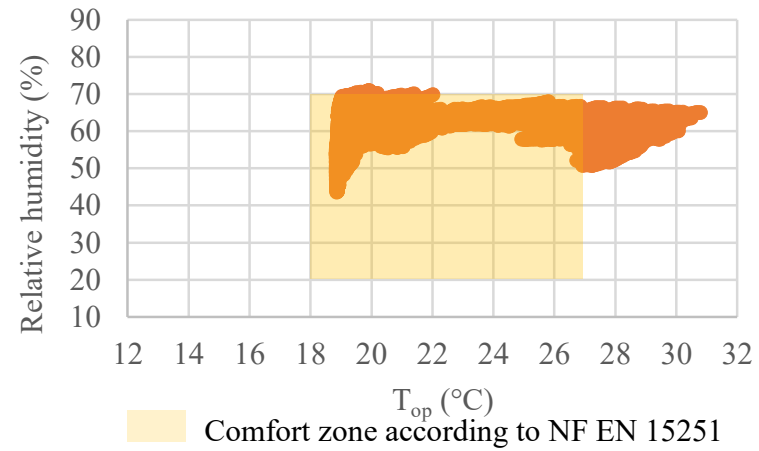

Fig. 13. Relative humidity and operative temperature in the room with the spruce panelling.

For the sake of clarity, the number of hours and the associated percentage, spent in the comfort zone, regarding either the operative temperature or the relative humidity or both of them, has been calculated for both rooms, over a year $(8760 \mathrm{~h})$. They are presented in Table 5.

Table 5. Time spent in the comfort zone.

\begin{tabular}{ccc}
\hline \hline & $\begin{array}{c}\text { Gypsum } \\
\text { room }\end{array}$ & $\begin{array}{c}\text { Spruce } \\
\text { room }\end{array}$ \\
\hline $18^{\circ} \mathrm{C}<\mathrm{T}_{\text {op }}<27^{\circ} \mathrm{C}$ & $\begin{array}{c}7420 \mathrm{~h} \\
(84.7 \%)\end{array}$ & $\begin{array}{c}7279 \mathrm{~h} \\
(83.1 \%)\end{array}$ \\
\hline $20 \%<\mathrm{RH}<70 \%$ & $\begin{array}{c}7302 \mathrm{~h} \\
(83.3 \%)\end{array}$ & $\begin{array}{c}8728 \mathrm{~h} \\
(99.6 \%)\end{array}$ \\
\hline $18^{\circ} \mathrm{C}<\mathrm{T}_{\mathrm{op}}<27^{\circ} \mathrm{C}$ & & \\
and & $6085 \mathrm{~h}$ & $7246 \mathrm{~h}$ \\
$20 \%<\mathrm{RH}<70 \%$ & $(69.5 \%)$ & $(82.7 \%)$ \\
\hline \hline
\end{tabular}

Considering only the operative temperature, the results are similar, with a little less than $85 \%$ of the time spent in the comfort zone for both rooms. However, regarding the relative humidity, the difference between both rooms is greater. Still $85 \%$ of the time is spent in the comfort zone for the room with plasterboards but it reaches almost $100 \%$ for the wooden room. Finally, the combination of these two criteria leads to the following conclusion: almost $70 \%$ of the time fulfills the requirements concerning comfort in the room with the plasterboards against more than $80 \%$ in the wooden room. Thus, the wooden room seems to be more comfortable than the gypsum one, according to the NF EN 15251.

It is also interesting to look at the hours out of the comfort zone and study how strong is the discomfort. To do so regarding the operative temperature, Equation 6 is calculated over the year.

$$
\sum_{\substack{i=\text { hours out of } \\ \text { the comfort zone }}} T_{o p_{i}}-27
$$

A similar analysis can be done for the relative humidity, according to Equation 7.

$$
\sum_{\begin{array}{c}
i=\text { hours out of } \\
\text { the comfort zone }
\end{array}} R H_{i}-70
$$

The results are presented in Table 6 .

Table 6. The intensity of the discomfort.

\begin{tabular}{ccc}
\hline \hline & $\begin{array}{c}\text { Gypsum } \\
\text { room }\end{array}$ & $\begin{array}{c}\text { Spruce } \\
\text { room }\end{array}$ \\
\hline Regarding $\mathrm{T}_{\mathrm{op}}$ & $1553^{\circ} \mathrm{C} . \mathrm{h}$ & $1453^{\circ} \mathrm{C} . \mathrm{h}$ \\
\hline Regarding $\mathrm{RH}$ & $6725 \% . \mathrm{h}$ & $11 \% . \mathrm{h}$ \\
\hline \hline
\end{tabular}

Concerning the operative temperature, according to Table 5, there are fewer hours in the comfort zone for the Spruce room than for the Gypsum room, but according to Table 6, during the hours out of the comfort zone, the discomfort in the Spruce room is less intense than in the Gypsum room.

Concerning the relative humidity, the discomfort due to high relative humidity is negligible for the Spruce room, while it remains significant for the Gypsum room.

\section{Conclusion}

The water vapour exchanges between the surface of indoor cladding materials and the air have to be taken into account by the simulations tools to model the indoor environment correctly. Indeed, as this mass exchange comes along with latent heat exchange, it affects the surface temperature of the materials. Then, as the surface temperature is a key parameter to define the convective and radiative heat exchanges with the air, a false estimation of the surface temperature leads to a false estimation of the air temperature, particularly during 
summer. The study presented in this article shows that this difference in thermal behaviour is due to the latent heat of sorption exchanges during summer. The more hygroscopic the indoor cladding materials, the greater the differences.

In addition, previous works have shown that this mass exchange also impacts the relative humidity level in the room. The effect of moisture buffering has therefore been investigated from both a thermal and a hygric point of view, as well as a hygrothermal point of view.

The use of hygroscopic materials in summer leads to both a reduction in the number of hours out of the comfort zone and a lower intensity of discomfort over the hours out of the comfort zone. Thus, the choice of indoor cladding materials has an impact on the indoor environment and can, therefore, really affect the comfort perceived by the occupants.

To complete this numerical study, there are ongoing experimental measurements in the house presented in Figure 1. These experimental data will allow us to refine our numerical hypotheses, as for instance the values of the heat transfer resistances. Other occupancy schedules and ventilation rates will also be tested to better understand the impact of indoor cladding materials on the indoor environment.

This work was funded by French Environment Management Agency (ADEME) and Smart-reno program supported by French Certificats d'Economie d'Energie (CEE).

\section{Nomenclature}

$\begin{array}{ll}\Delta \text { latent }_{\mathrm{Tsurf}} & \begin{array}{l}\text { Difference between the surface } \\ \text { temperature without latent heat and the } \\ \text { surface temperature with latent heat }\left({ }^{\circ} \mathrm{C}\right)\end{array} \\ \mathrm{T}_{\text {air }} & \text { Air temperature }\left({ }^{\circ} \mathrm{C}\right) \\ \Delta \mathrm{T}_{\text {air }} & \text { Difference in air temperature }\left({ }^{\circ} \mathrm{C}\right) \\ \mathrm{T}_{\mathrm{mr}} & \text { Mean radiant temperature }\left({ }^{\circ} \mathrm{C}\right) \\ \mathrm{T}_{\mathrm{op}} & \text { Operative temperature }\left({ }^{\circ} \mathrm{C}\right) \\ \Delta \mathrm{T}_{\mathrm{op}} & \text { Difference in operative temperature }\left({ }^{\circ} \mathrm{C}\right) \\ \mathrm{T}_{\text {surf }} & \text { Surface temperature }\left({ }^{\circ} \mathrm{C}\right) \\ \Delta \mathrm{T}_{\text {surf }} & \text { Difference in surface temperature }\left({ }^{\circ} \mathrm{C}\right)\end{array}$

\section{References}

1. A. Q. Nyrud, T. Bringslimark, Wood Fiber Sci., 42(2), 202-218 (2010)

2. S. R. Bhatta, K. Tiippana, K. Vahtikari, P. Kiviluoma, M. Hughes, M. Kyttä, Energy Build., 195, 26-32 (2019)

3. J. Rice, Wood Fiber Sci., 38, 644-659 (2006)

4. S. Boulet, $\mathrm{PhD}$ thesis (2009)

5. NF EN ISO 7730, AFNOR (2005)

6. T. Ojanen, Int. J. Hous. Sci. Its Appl., 40, 159-169 (2016)

7. C. Legros, M. Cosnier, A. Piot, M. Pailha, M. Woloszyn, Proceedings of Building Simulation: $16^{\text {th }}$ Conference of IBPSA (IBPSA 2019, Rome, to be published)

8. A. Sommet, https://biologiedelapeau.fr (2019)

9. NF EN ISO 7726, AFNOR, (2002)

10. D. Wang, G. Chen, C. Song, Y. Liu, W. He, T. Zeng, J. Liu, Build. Environ., 165, 106387 (2019)

11. D. Kraniotis, N. Langouet, T. Orskaug, K. Nore, G. Glasø, WTCE 2016 Proceedings, (WTCE, Vienna, 2016)

12. K. Nore, A. Q. Nyrud, D. Kraniotis, K. R. Skulberg, F. Englund, T. Aurlien, Sci. Technol. Built Environ., 23(3), 512-521 (2017)

13. H. M. Künzel, A. Holm, D. Zirkelbach, A. N. Karagiozis, Sol. Energy, 78(4), 554-561 (2005)

14. F. Antretter, F. Sauer, T. Schöpfer, A. Holm, Proceedings of Building Simulation 2011: $12^{\text {th }}$ Conference of IBPSA (IBPSA 2011, Sydney, 2011)

15. NF EN ISO 6946, AFNOR (2017)

16. NF EN 15251, AFNOR (2007) 